\title{
Two-Mode Controlled Single/Dual-Input DC-AC Inverter with Wide-range DC Input
}

\author{
Zhang, Zhe; Chen, Xuefeng
}

Published in:

I E E E Transactions on Power Electronics

Link to article, DOI:

10.1109/TPEL.2020.3027244

Publication date:

2021

Document Version

Peer reviewed version

Link back to DTU Orbit

Citation $(A P A)$ :

Zhang, Z., \& Chen, X. (2021). Two-Mode Controlled Single/Dual-Input DC-AC Inverter with Wide-range DC Input. I E E E Transactions on Power Electronics, 36. https://doi.org/10.1109/TPEL.2020.3027244

\section{General rights}

Copyright and moral rights for the publications made accessible in the public portal are retained by the authors and/or other copyright owners and it is a condition of accessing publications that users recognise and abide by the legal requirements associated with these rights.

- Users may download and print one copy of any publication from the public portal for the purpose of private study or research.

- You may not further distribute the material or use it for any profit-making activity or commercial gain

- You may freely distribute the URL identifying the publication in the public portal

If you believe that this document breaches copyright please contact us providing details, and we will remove access to the work immediately and investigate your claim. 


\title{
Two-Mode Controlled Single/Dual-Input DC-AC Inverter with Wide-Range DC Input
}

\author{
Xuefeng Chen, Member, IEEE and Zhe Zhang, Senior Member, IEEE
}

\begin{abstract}
-this paper presents a two-mode controlled step-up inverter (TMCSI), which is capable of handling single or dual inputs with a wide range of dc input voltage. In comparison of traditional multi-stage $\mathrm{dc} / \mathrm{dc}$ power conversion systems, the power conversion stage is reduced and the voltage/current stress of device is significantly alleviated without using high-voltage dc-bus capacitors. As a result, the reliability and overall conversion efficiency are improved accordingly. By combining the two working modes, the proposed inverter achieves uniform distribution of duty ratio under single/dual-input with a wide range of input voltage, and thereby is very suitable for systems having large input voltage variation. Moreover, based on the dual-input TMCSI a novel power allocation method is also proposed to improve the system load-bearing ability. The power allocation method is controlled separately from two working modes that allows the two-input sources directly supply the ac load simultaneously. In this paper, topology derivation, two-mode control strategy, characteristics of steady principle and design criteria for the key circuit parameters are systematically analyzed, and important conclusions are obtained. Finally, the experimental results from the single/dual-input 500VA 96-192VDC input and $220 \mathrm{VAC} / 50 \mathrm{~Hz}$ output inverter prototype verify the effectiveness of the proposed TMCSI topology and its associated power regulation approach.
\end{abstract}

Index Terms-Buck-Boost converter, full bridge inverter, step-up inverter, two-mode control, wide range input voltage

\section{NOMENCLATURE}

$D_{\mathrm{Ssn}} \quad$ Duty ratio of selective switch $\mathrm{S}_{\mathrm{s} n}$.

$d_{1} / d_{\mathrm{ST} 1} \quad$ Duty ratio of full-bridge inverter/ buck-boost converter.

$u_{\mathrm{ab}} \quad$ Output voltage of full bridge.

$u_{\mathrm{i} 1} / u_{\mathrm{i} 2} \quad$ Output voltage of two input units.

$U_{\mathrm{i} n} / I_{\mathrm{i} n} \quad$ Output voltage/current of the input source $n$.

$U_{\text {os }} \quad$ High-frequency switching voltage $U_{\mathrm{os}}=\left(D_{\mathrm{Ss} 1} U_{\mathrm{i} 1}+D_{\mathrm{Ss} 2} U_{\mathrm{i} 2}\right)$.

$P_{\text {ilm }} \quad$ Maximum output power of PV cells.

$U_{\text {ilM }} \quad$ PV's output voltage at maximum power point.

$U_{\text {il_ref }} \quad$ Reference voltage for PV cells.

$I_{\text {il_ref }} \quad$ Reference current for PV cells.

$P_{\mathrm{o}} \quad$ Output power of the inverter.

$k \quad$ Output value of the voltage regulator.

$K_{\mathrm{m}} \quad$ Maximum value of $k$.

$u_{\mathrm{sn}} \quad$ Modulation signal of carrier waveform.

$U_{\mathrm{cm}} \quad$ Amplitude of carrier waveform.

$p_{\mathrm{i} 1} / p_{\mathrm{i} 2} \quad$ Output power of the two input sources $U_{\mathrm{i} 1} / U_{\mathrm{i} 2}$.

$I_{\text {Llavg }} \quad$ Average current of inductor $L_{1}$.

Manuscript received, on 08 Mar. 2020; revised on 3 June and 28 Jul. 2020 accepted on10 Sept. 2020. (Corresponding author: Zhe Zhang)

Xuefeng Chen is with the Department of Electrical Engineering, Fuzhou University, Fuzhou, China. (Email: cxf199401@163.com).

Zhe Zhang with the Department of Electrical Engineering, Technical University of Denmark, Kgs. Lyngby, Denmark, 2800. (Email: zz@elektro.dtu.dk).

\section{INTRODUCTION}

Nowadays applying renewable energies to distributed generation, transportation, multi-energy systems etc, has become a key technology for future developments towards a fossil-free society. Dc-ac inverters have significance of power transforming for ac load or grid, and thereby are critical in the application of solar energy, wind and hydrogen.

Many researches have been done to pursue both high conversion efficiency and high ac quality in a hybrid system with multiple and various dc inputs, such as photovoltaics, fuel cells and batteries [1]-[4]. Usually a step-up function is needed in such dc-ac power conversion systems [3], [4]. The traditional low-frequency link inverter proposed in [5], [6] is cascaded by full/half-bridge inverter and a step-up line-frequency transformer. It inherits buck-type inverters' advantages, e.g. high efficiency, high reliability, simple modulation and control; however, an inverter system employing line-frequency $(50 / 60 \mathrm{~Hz})$ transformers, suffers from high cost, bulky size and loud acoustic noise. Ref. [7] and [8] presented a multi-stage dc-ac power system, including: 1) the conventional two-stage dc-ac power system in [9] and [10], which consists of a boost converter as the front-end dc-dc step-up converter and a full/half-bridge inverter; 2) the multi-stage high-frequency link (HFL) inverter proposed in [11] and [12], which is configured by a dc-dc converter with a high-frequency transformer and a full-bridge inverter, in which bidirectional switches are normally adopted; 3) the differential-mode HFL inverter presented in [13] and [14], which connects the output of two identical HFL dc-dc converters in a differential output. These cascade-connected conversion systems have a relatively high voltage boosting ability, but induce high conduction and switching losses, so that the overall efficiency suffers.

On the other hand, when these inverters are powered by renewable or clean energy sources that have varied output voltage due to the random and intermittent characteristics e.g. photovoltaics, or their inherent electrochemical features e.g. fuel cells, the overall power conversion efficiency suffers because the wide input voltage range causes a narrow or even extreme duty ratio regulating range under a ultra-high or low input voltage. The quasi- $Z$ source inverter, as a single-stage converter, proposed in [15], [16] can handle wide-range input voltage, and has less number of active switches and high quality ac output waveform, but high current and voltage stresses over active switches, bulky passive components and complicated control make it difficult to achieve high efficiency and low cost for matching the demand of the large-scale usage in mass production. A new concept of dual-dc-port asymmetrical multilevel inverter (DP-AMI) is studied in [17]. Due to the asymmetrical multiple voltage levels generated in the inverter, the proposed DP-AMI can achieve reduced number of power stages as well as lower voltage/current stresses over switches. In [18]-[20], the promising multilevel inverters in medium and high power 
IEEE POWER ELECTRONICS REGULAR PAPER/LETTER/CORRESPONDENCE.

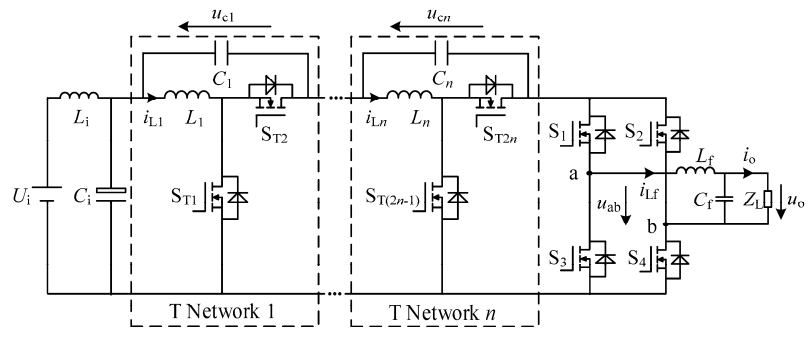

Fig. 1. Topology of TMCSI-BBC.

Applications are proposed, which can handle the series-connected separate dc-voltage source or regulated voltage from the conventional dc-dc converter for ac load supply, and generate high-quality staircase pseudo sinusoidal voltage waveform with low total harmonic distortion. These multilevel inverters allow use of less sizable output filters and offer robust, efficient, and fault-tolerant features.

The major contribution of this paper is to propose a new family of a two-mode controlled step-up inverter (TMCSI) and its associated control strategy. The proposed dc-ac power system has following advantages.

1) Both the number of power conversion stages and the voltage/current stress of devices are reduced without using high-voltage bus capacitors that is beneficial for improving efficiency and reducing converter size/volume.

2) Using the two working modes, the proposed inverter can be effectively used in the application of wide-range input voltage for a uniform distribution of duty ratio under input voltage variation.

3) A TMCSI-based dual-input inverter with a power allocation control is proposed. This dual-input inverter allows two input dc sources to directly supply an ac load simultaneously, and also inherits the advantages of the two-mode control method, which help to achieve the uniform distribution of duty ratio under single- or dual-input operation. Therefore, semiconductors' current stress is reduced significantly.

This paper is organized as follows. After the introduction, Section II presents the derivation of the proposed TMCSI and its topology family. Section III provides the analysis of two-mode control strategy and operation principle under single- and dual-input. Section IV discusses the proposed inverter's characteristics and its design considerations. Section $\mathrm{V}$ gives experimental results to verify the theoretical analysis and design. Finally, Section VI summarizes the major conclusions of this paper.

\section{THE PROPOSED TMCSI AND ITS TOPOLOGY FAMILY}

The proposed TMCSI is shown in Fig. 1, which consists of $n$ T-networks and a full-bridge inverter. The more the number of T-network is, the higher voltage gain i.e. the lower input voltage that the inverter can have. The T-network is actually a Buck/Boost dc circuit that composes of inductor $L_{1}$, capacitor $C_{1}$ and power switches $S_{\mathrm{T} 1}, S_{\mathrm{T} 2}$. It can realize bidirectional power transforming as well as boost input voltage. It is noteworthy that the shoot through issue of H-bridges can be avoided due to the T-network circuit that results in high system reliability. Therefore, the proposed inverter based on Buck/Boost converter (BBC) can also be called as TMCSI-BBC. Taking $n=1$ and positive cycle of output voltage $u_{\mathrm{o}}$ as an example, there are two working modes.

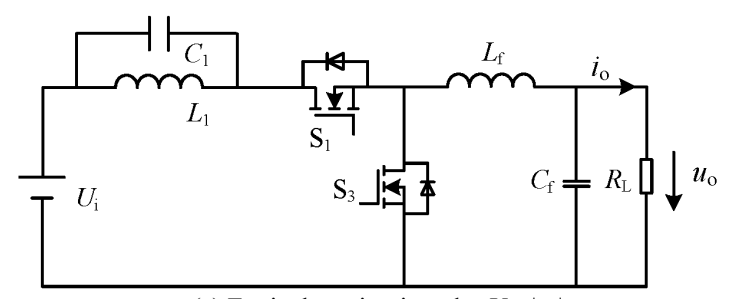

(a) Equivalent circuit under $U_{\mathrm{i}}>\left|u_{\mathrm{o}}\right|$

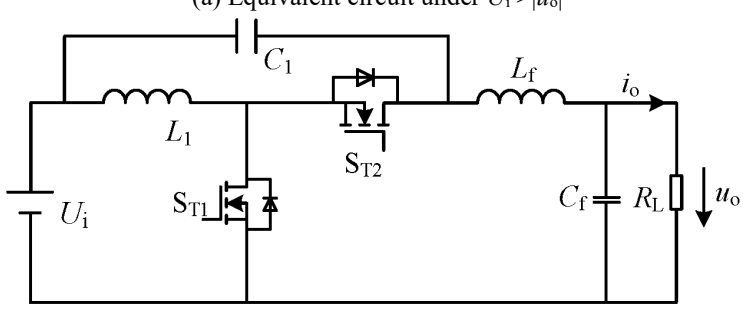

(b) Equivalent circuit under $U_{\mathrm{i}}<\left|u_{\mathrm{o}}\right|$

Fig. 2. Equivalent circuit of the proposed TMCSI-BBC.

Mode I: when $U_{\mathrm{i}}>$ the absolute value $\left|u_{\mathrm{o}}\right|, S_{\mathrm{T} 1}$ keeps OFF and $S_{\mathrm{T} 2}$ is $\mathrm{ON}$. The full-bridge inverter is controlled by sinusoidal pulse width modulation (SPWM), and the output $u_{\mathrm{ab}}$ is a PWM waveform. Its equivalent circuit is plotted in Fig. 2(a). It can be seen that a new power flow path between the low-voltage input $U_{\mathrm{i}}$ and ac output side is constructed that allows $U_{\mathrm{i}}$ to supply the load directly due to the low impedance characteristic of the intermediate capacitive link under high frequency.

Mode II: When $U_{\mathrm{i}}<\left|u_{\mathrm{o}}\right|$, the T-network has complementary SPWM switching, $U_{\mathrm{i}}$ and $C_{1}$ supply the load in series, and at the same time the full-bridge inverter works in a low frequency polar-inversion manner, as shown in Fig. 2(b).

Therefore, the regulation of ac output voltage can be realized by combing the two working modes and shifting between these two modes based upon the voltage relationship of $U_{\mathrm{i}}$ and $\left|u_{\mathrm{o}}\right|$.

Besides the T-network structure, the proposed two-mode control can be extended further to the $\mathrm{Z}$-source inverter and its derivatives. By replacing $C_{1}$ and $C_{2}$ with small film capacitors, the conventional Z-source inverter can be controlled by the same aforementioned two-mode control approach. As a result, the voltage and current stress on both $L_{1}, L_{2}$ and the power switches is reduced that can decrease component size and cost, as well as improve the overall converter efficiency. When $U_{\mathrm{i}}>\left|u_{\mathrm{o}}\right|$, the full-bridge inverter works with SPWM, as shown in Fig. 3. When $U_{\mathrm{i}}<\left|u_{\mathrm{o}}\right|$, the shoot-through duty ratio of the full-bridge inverter legs can be regulated to boost $U_{\mathrm{i}}$. By combining these two working modes, the output voltage inversion is achieved. Therefore, this proposed TMCSI based on the simplified Z-network can be called TMCSI-ZN. The topology of quasi-Z source inverter is shown in Fig. 4 (a), the two-mode control can also be used as TMCSI-ZN does. To obtain higher boost ability, the topology can be changed as shown in Fig. 4(b), and this proposed TMCSI based on the simplified quasi-Z-network can then be called as TMCSI-QZ.

Moreover, the proposed topology family can be extended to multiple-input inverters. Therefore, an additional input can be added to the proposed TMCSI-BBC, and forms a dual-input inverter as shown in Fig 5 and the $2^{\text {nd }}$ input is recommended to be connected in series with $L_{1}$. The two inputs of $U_{\mathrm{i} 1}$ and $U_{\mathrm{i} 2}$ can supply the ac load simultaneously. 
IEEE POWER ELECTRONICS REGULAR PAPER/LETTER/CORRESPONDENCE.

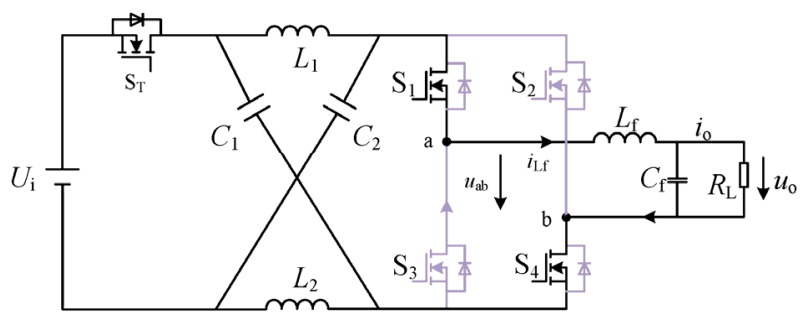

(a) Equivalent circuit I

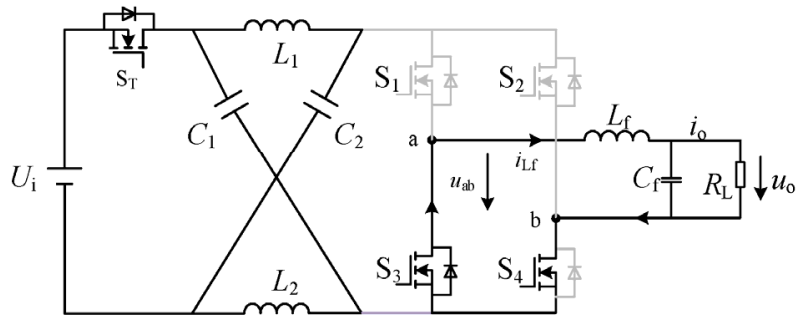

(b) Equivalent circuit II

Fig. 3. Equivalent circuit of TMCSI-ZN under $U_{\mathrm{i}}>\left|u_{\mathrm{o}}\right|$.

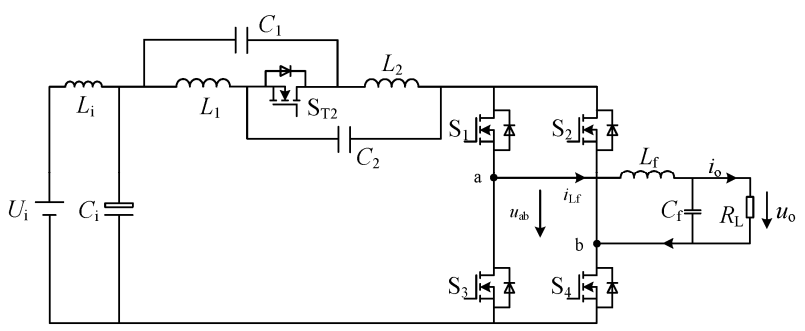

(a) Quasi-Z source inverter

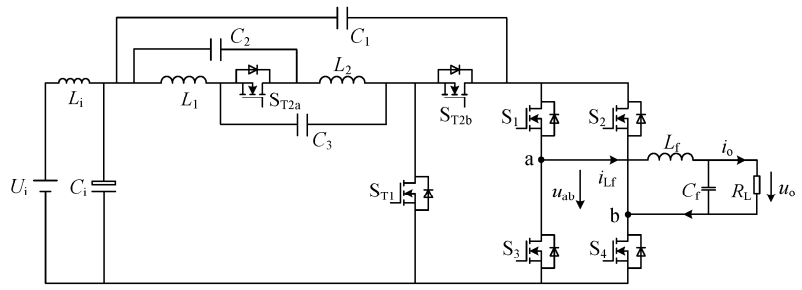

(b) TMCSI-QZ

Fig. 4. Topology of the proposed TMCSI based on quasi-Z network.

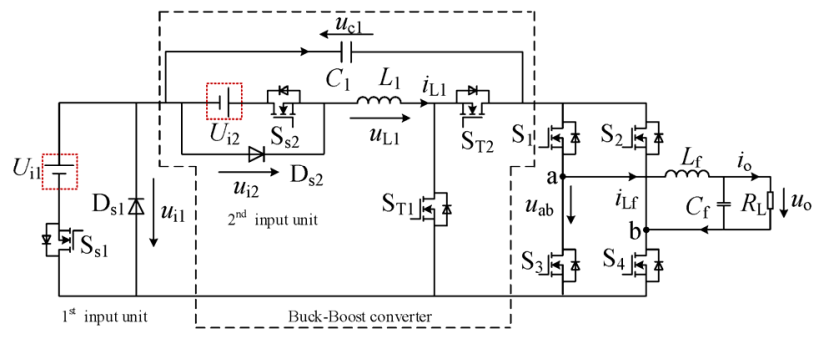

Fig. 5. Topology of the proposed dual-input inverter based on TMCSI-BBC.

More generally speaking, if the power allocation among $n$ input sources is needed, each input source $U_{\text {in }}$ should be equipped with a corresponding selective switch $\mathrm{S}_{\mathrm{s} n}$ and a by-pass diode $D_{\mathrm{s} n}$. By regulating the duty ratio $\left(d_{\mathrm{Ssn}}\right)$ of $\mathrm{S}_{\mathrm{s} n}$ with the line frequency $(L F) f_{\mathrm{o}}$ of $50 \mathrm{~Hz}$, and $f_{\mathrm{o}}<<f_{\mathrm{c}}$ (PWM carrier frequency), the converter can realize power allocation between input sources.

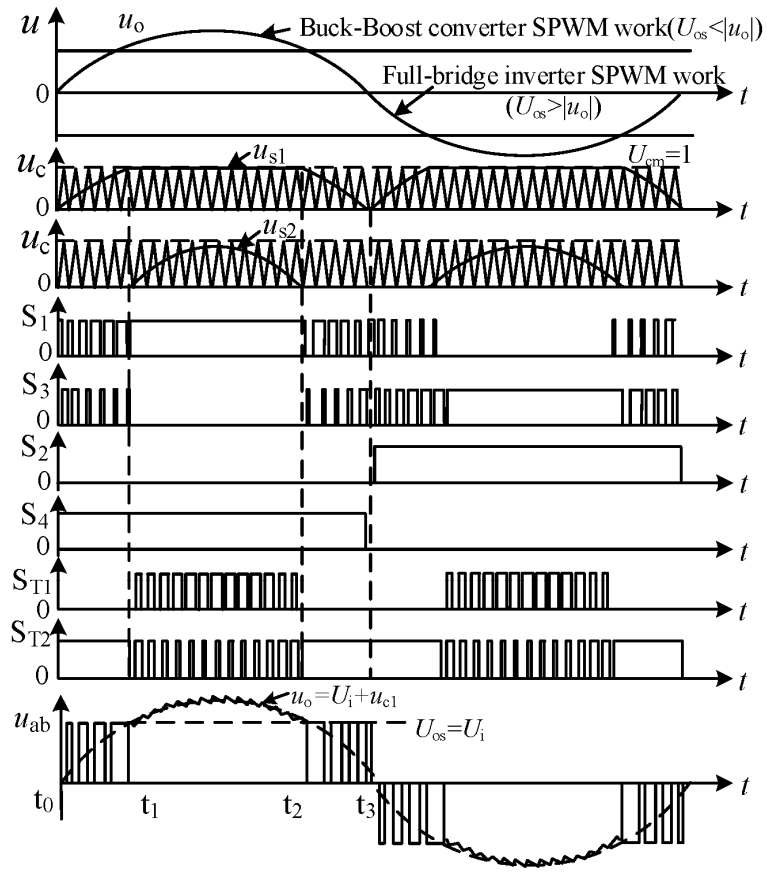

Fig. 6. Typical waveforms of two-mode control strategy.

\section{TWO-MOde CONTROL STRATEGY AND OPERATION PRINCIPLE}

The operation principle of two-mode control strategy under single input and dual inputs is the same. Nevertheless, power allocation control is needed for the two input sources in the dual-input case.

\section{A. Two-mode control strategy}

Taking the proposed TMCSI-BBC with single input as an example, the typical waveforms of two-mode control strategy are shown in Fig. 6. Due to symmetry of an entire sinusoidal period of $u_{\mathrm{o}}$, only the positive half cycle is analyzed, where $S_{4}$ remains ON and $S_{2}$ is OFF. When $\left|u_{0}\right|$ is lower than the switching voltage $U_{\mathrm{os}}=U_{\mathrm{i}}, S_{\mathrm{T} 1}$ and $S_{\mathrm{T} 2}$ always keep OFF and $\mathrm{ON}$, respectively. The full-bridge inverter is controlled by SPWM, and the output $u_{\mathrm{ab}}$ is a PWM waveform.

However, when $\left|u_{\mathrm{o}}\right| \geq U_{\mathrm{os}}=U_{\mathrm{i}}, S_{1}$ and $S_{3}$ keep ON and OFF, respectively. $S_{\mathrm{T} 1}$ and $S_{\mathrm{T} 2}$ of Buck/Boost converter work with complementary SPWM driving signals, and $u_{\mathrm{ab}}=U_{\mathrm{i}}+u_{\mathrm{c} 1}$ to realize boosting the input voltage. By combining these two operation modes i.e. full-bridge mode and Buck/Boost mode, depending on $\left|u_{\mathrm{o}}\right|$ and $U_{\mathrm{os}}=U_{\mathrm{i}}$, the inverter can output ac sinusoidal voltage.

\section{B. Operation principles for the dual-input system}

For the dual-input operation, based on the proposed two-mode control strategy, power allocation for the two input sources is also needed by adjusting the duty ratio $\left(d_{\mathrm{Ss} n}\right)$ of $S_{\mathrm{sn}}$. For example, if $U_{\mathrm{i} 1}$ and $U_{\mathrm{i} 2}$ employ photovoltaic (PV) cells and fuel cells as the input sources, respectively, a master-slave energy management is adopted to achieve the full use of power generated from PV. Namely, the $1^{\text {st }}$ input $U_{\mathrm{i} 1}$ is chosen as the master power supply and need tracking its maximum power point (MPP), and the $2^{\text {nd }}$ input $U_{\mathrm{i} 2}$ with adjustable output power supplements the power difference between the first input $U_{\mathrm{i} 1}$ and the load in off-grid systems. 
IEEE POWER ELECTRONICS REGULAR PAPER/LETTER/CORRESPONDENCE.

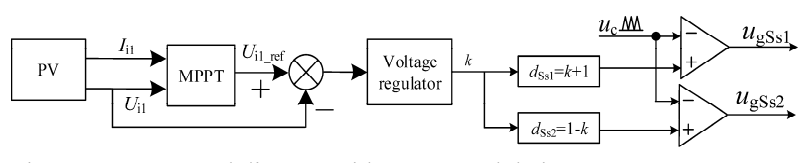

Fig. 7. MPPT control diagram with PWM modulation.

However, there is no power flow between the two input sources, and therefore the unidirectional renewable sources such as fuel cells, PVs or wind hybrid system are preferably used as an input.

The MPPT control diagram with PWM modulation is shown in Fig. 7, PV's output voltage $U_{\mathrm{i} 1}$ and current $I_{\mathrm{i} 1}$ is sampled and its reference voltage $U_{\text {il_ref }}$ will be calculated by an MPPT algorithm. $U_{\text {i1 }}$ is controlled to follow $U_{\text {il_ef }}$ by a voltage regulator with an output of $k$. Then the duty ratio $\left(d_{\mathrm{Ssn}}\right)$ of $S_{\mathrm{s} n}$ is obtained as $d_{\mathrm{ss} 1}=k+1$ and $d_{\mathrm{ss} 2}=1-k$, the driver signal of $S_{\mathrm{s} n}$ is obtained by the PWM modulation. Power allocation between the two inputs is directly controlled by the voltage regulator for PV's MPPT, it makes the control system relatively simple and reliable [20]. Usually the MPPT control loop does not require high control bandwidth, which is set as $f_{\mathrm{o}}=50 \mathrm{~Hz}$ in this paper, so $d_{\mathrm{ssn}}$ can be considered as a constant value of $D_{\text {Ssn }}$ in a LF period, as shown in Fig. 8. According to the relationship between the maximum power $P_{\mathrm{i} 1 \mathrm{M}}$ provided by $U_{\mathrm{i} 1}$ and the ac load $P_{\mathrm{o}}$, the proposed dual-input inverter has two operating states, as shown in Fig. 8(a) and (b), respectively. Each operating state consists of two working modes, and their equivalent circuits are shown in Fig. 9. $\mathrm{K}_{\mathrm{m}}>1$ is the maximum value of $|k|$.

1) State I [see Fig. 8(a)]: If $P_{\mathrm{i} 1 \mathrm{M}}>P_{\mathrm{o}}, U_{\mathrm{i} 1}$ will supply the load alone. PV output voltage $U_{\mathrm{i} 1}$ is larger than $U_{\mathrm{il} \text { ref }}$ and $k$ is clamped at $\mathrm{K}_{\mathrm{m}}$ by the voltage regulator. So $\left(D_{\mathrm{Ss} 1}=1+k\right)>1$ is clamped at $D_{\mathrm{Ss} 1}=1$, and then $D_{\mathrm{Ss} 2}=1-k=0$. Namely, $S_{\mathrm{s} 1}$ keeps $\mathrm{ON}$, and $S_{\mathrm{s} 2}$ is OFF. Decreasing $P_{\mathrm{i} 1 \mathrm{M}}$ to $P_{\mathrm{o}} \geq P_{\mathrm{i} 1 \mathrm{M}} \geq P_{\mathrm{o}} U_{\mathrm{i} 1 \mathrm{M}} /\left(U_{\mathrm{i} 1 \mathrm{M}}+U_{\mathrm{i} 2}\right)$, and $U_{\mathrm{i} 1}$ is not sufficient to support the load alone, $k$ will be regulated from 1 to 0 by the voltage regulator. While $D_{\mathrm{Ss} 1}$ is still clamped at 1 and $1 \geq D_{\mathrm{Ss} 2} \geq 0$, which means $S_{\mathrm{s} 1}$ remains ON. The part of $P_{\mathrm{o}}$ provided by $U_{\mathrm{i} 2}$ is adjusted by $D_{\mathrm{Ss} 2}$, which help $U_{\mathrm{i} 1}$ to track its MPP. Since $D_{\text {Ssn }}$ is almost a constant value in a LF period, $U_{\text {os }}$ can be expressed as $U_{\mathrm{os}}=U_{\mathrm{i} 1}+D_{\mathrm{Ss} 2} U_{\mathrm{i} 2}$ in State I.

Buck mode [Interval $t_{0}-t_{1}$ and $t_{2}-t_{3}$ ]: when $u_{\mathrm{o}} \leq U_{\mathrm{os}}$, in this mode, $S_{\mathrm{T} 1}$ keeps OFF, $S_{\mathrm{T} 2} \mathrm{ON}$, only the full-bridge inverter SPWM works, and its equivalent circuit is A shown in Fig. 9 (a).

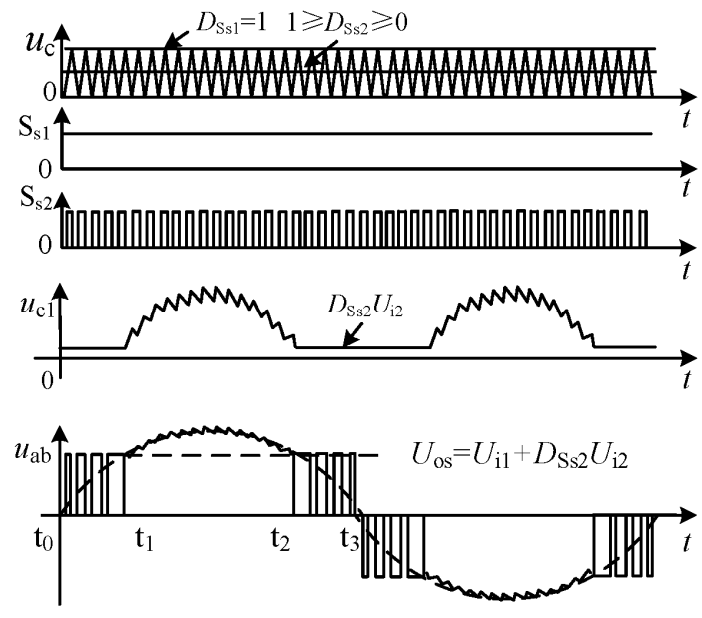

(a) State I: $\mathrm{K}_{\mathrm{m}} \geq k \geq 0$
Buck-Boost mode [Interval $t_{1}-t_{2}$ ]: when $u_{\mathrm{o}}>U_{\text {os }}, S_{1}$ keeps on, $S_{3}$ is OFF, only the Buck/Boost converter works with complementary SPWM switching. $U_{\mathrm{i} 1}$ and $C_{1}$ in series supply the load, shown as the equivalent circuit $\mathrm{C}$ in Fig. 9 (b).

2) State II [see Fig. 8(b)]: If $P_{\text {i1 }}$ provided by $U_{\mathrm{i} 1}$ continues to decrease below $P_{\mathrm{o}} U_{\mathrm{ilM}} /\left(U_{\mathrm{ilM}}+U_{\mathrm{i} 2}\right)>P_{\mathrm{i} 1 \mathrm{M}}, k$ will be regulated from 0 to $-\mathrm{K}_{\mathrm{m}}$. Thus $D_{\mathrm{Ss} 2}=1-k$ is clamped to $D_{\mathrm{Ss} 2}=1$, and $1>D_{\mathrm{Ss} 1} \geq 0$, which means $S_{\mathrm{s} 2}$ keeps $\mathrm{ON}$, the part of $P_{\mathrm{o}}$ provided by $U_{\mathrm{i} 1}$ is regulated by $D_{\mathrm{Ss} 1}$, and makes $U_{\mathrm{i} 1}$ track MPP, and $U_{\mathrm{i} 2}$ supplements the power difference between $P_{\mathrm{i} 1 \mathrm{M}}$ and $P_{\mathrm{o}} . U_{\mathrm{os}}$ can be expressed as $U_{\mathrm{os}}=D_{\mathrm{Ss} 1} U_{\mathrm{i} 1}+U_{\mathrm{i} 2}$ in State II.

Buck mode [Interval $t_{\mathrm{a}}-t_{\mathrm{b}}$ and $t_{\mathrm{c}}-t_{\mathrm{d}}$ ]: $u_{\mathrm{o}} \leq U_{\mathrm{os}}$, it is the same as in State I, i.e. the full-bridge inverter works, and its equivalent circuit B is shown in Fig.9 (a).

Buck-Boost mode [Interval $t_{\mathrm{b}}-t_{\mathrm{c}}$ ]: $u_{\mathrm{o}}>U_{\text {os }}$, the Buck/Boost converter works, $D_{\mathrm{Ss} 1} U_{\mathrm{il}}$ and $C_{1}$ supply the load in series, and its equivalent circuit D is shown in Fig. 9 (b).

In summary, when $P_{\mathrm{i} 1 \mathrm{M}}$ decreases, $k$ will decrease by the voltage regulator to reduce the output power of $U_{\mathrm{i} 1}$ and make $U_{\mathrm{i} 1}$ achieve MPPT, and vise versa. The dual-input system has two operating states, and each state consists of the two working modes, which have been listed in Table I. Combining the two working modes, the proposed inverter achieves voltage inversion under single/dual-input source.

The proposed control method is complex than the conventional multi-stage dc/ac power conversion system. However, it should be noted that at a certain time, only one pair of switches operate in high frequency that is in Buck mode: $S_{1}$ and $S_{3}$ (zero voltage switching-ZVS), or $S_{2}$ (ZVS) and $S_{4}$ in the positive and negative half cycles, respectively; in Buck-Boost mode: $S_{\mathrm{T} 1}$ and $S_{\mathrm{T} 2}$ (ZVS) in high frequency, and $S_{1} \sim S_{4}$ operate in line frequency. The Buck mode and Buck-Boost mode are controlled independently, which make the system have high reliability and simple control logic. Moreover, the proposed power allocation method for the two inputs is implemented separately from the two-mode control, therefore, in practice, this control under single-/dual-input can be easily realized using a digital signal processor.

\begin{tabular}{|c|c|c|c|c|c|}
\hline \multirow{2}{*}{$\begin{array}{c}\text { Operating } \\
\text { State } \\
\end{array}$} & \multirow{2}{*}{$k$} & \multirow{2}{*}{$D_{\mathrm{SS} 1}=k+1, \quad D_{\mathrm{Ss} 2}=1-k$} & \multicolumn{2}{|c|}{ Two Working Modes } & \multirow{2}{*}{$\begin{array}{l}\text { Typical Waveforms } \\
\text { in Fig. } 8\end{array}$} \\
\hline & & & Buck & Buck-Boost & \\
\hline I & $\mathrm{K}_{\mathrm{m}} \geqslant k \geqslant 0$ & $D_{\mathrm{Ss} 1}=1, \quad 1 \geqslant D_{\mathrm{Ss} 2} \geqslant 0$ & A & $\mathrm{C}$ & (a) \\
\hline II & $0>k \geqslant-\mathrm{K}_{\mathrm{m}}$ & $1 \geqslant D_{\mathrm{Ss} 1} \geqslant 0, \quad D_{\mathrm{Ss} 2}=1$ & B & D & (b) \\
\hline
\end{tabular}

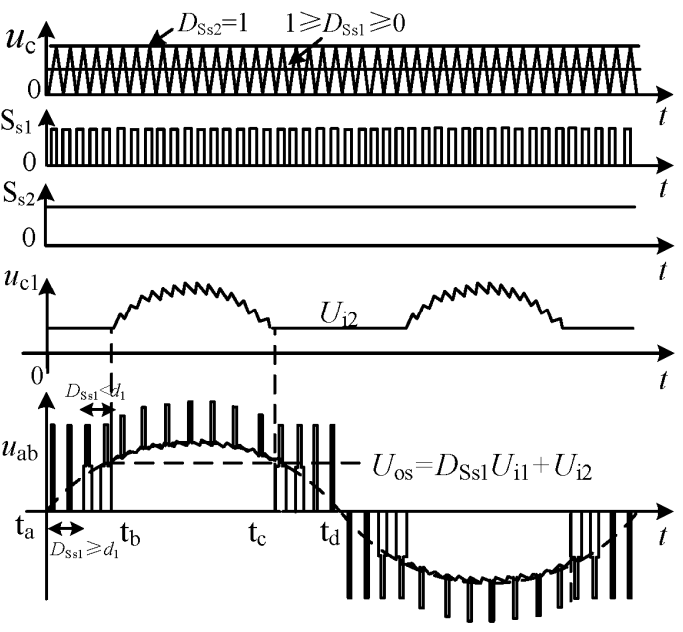

(b) State II: $0>k \geq-K_{m}$

Fig. 8. Typical waveforms of two operating states in a LF period. 


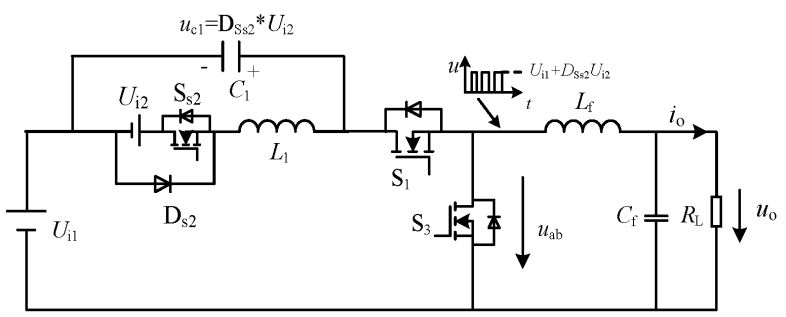

Equivalent circuit A

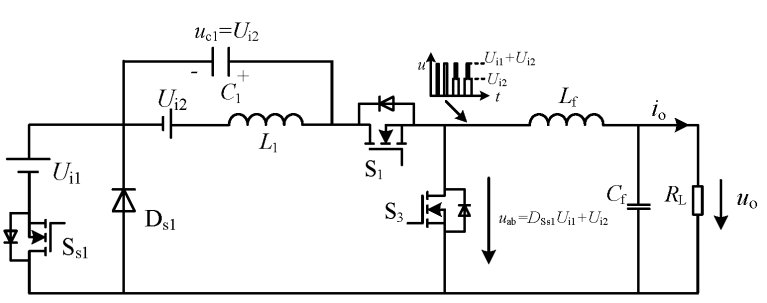

Equivalent circuit B

(a) Equivalent circuit in Buck mode.

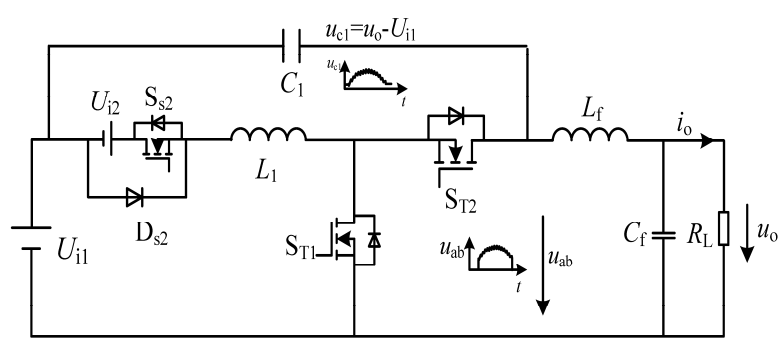

Equivalent circuit $\mathrm{C}$

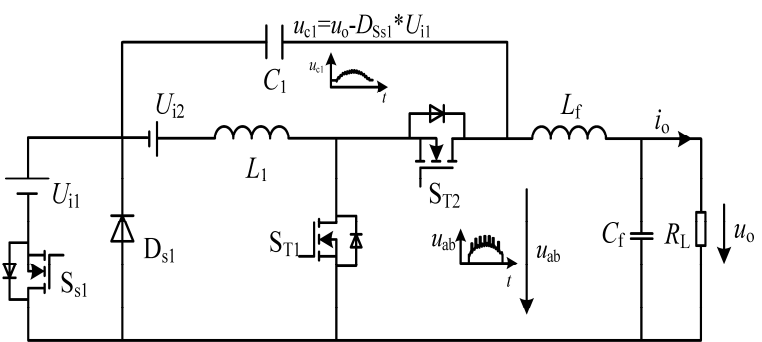

Equivalent circuit D

(b) Equivalent circuit in Buck-Boost mode

Fig. 9. Equivalent circuit of the proposed dual-input inverter.

\section{CHARACTERISTICS AND DESIGN CONSIDERATION}

\section{A. Output characteristics}

When the full-bridge inverter operates in steady state, the output voltage of $u_{\mathrm{o}}$ as a function of $U_{\mathrm{i} 1}$ and $U_{\mathrm{i} 2}$ can be expressed as

$$
u_{\mathrm{o}}=\left\{\begin{array}{cc}
d_{1}\left(U_{\mathrm{i} 1}+D_{\mathrm{Ss} 2} U_{\mathrm{i} 2}\right) & D_{\mathrm{Ss} 1} \geq d_{1} \\
D_{\mathrm{Ss} 1} U_{\mathrm{i} 1}+d_{1} D_{\mathrm{Ss} 2} U_{\mathrm{i} 2} & D_{\mathrm{Ss} 1}<d_{1}
\end{array}\right.
$$

where $d_{1}$ is the duty ratio of the full-bridge inverter. When the Buck-Boost converter operates, the output voltage is calculated by

$$
u_{\mathrm{o}}= \begin{cases}D_{\mathrm{Ss} 1} U_{\mathrm{i} 1}+\frac{d_{\mathrm{ST} 1} U_{\mathrm{i} 1}+D_{\mathrm{Ss} 2} U_{\mathrm{i} 2}}{1-d_{\mathrm{ST} 1}} & D_{\mathrm{Ss} 1} \geq d_{\mathrm{ST} 1} \\ D_{\mathrm{Ss} 1} U_{\mathrm{i} 1}+\frac{D_{\mathrm{Ss} 1} U_{\mathrm{i} 1}+D_{\mathrm{Ss} 2} U_{\mathrm{i} 2}}{1-d_{\mathrm{ST} 1}} & D_{\mathrm{Ss} 1}<d_{\mathrm{ST} 1}\end{cases}
$$

where $d_{\mathrm{ST} 1}$ is the duty ratio of the Buck-Boost converter.

Then switching voltage $U_{\text {os }}$ between the two working modes can be derived from (1) or (2), where $d_{1}=1$ or $d_{\mathrm{ST} 1}=0$.

$$
U_{\mathrm{os}}=D_{\mathrm{Ss} 1} U_{\mathrm{i} 1}+D_{\mathrm{Ss} 2} U_{\mathrm{i} 2}
$$

The corresponding output characteristic curves, which are obtained from (1) and (2), can be plotted in Fig. 10. It shows that $U_{\text {os }}$ increases with increasing $D_{\text {Ssn }}$, and the working time of full-bridge inverter becomes longer, and conversely the Buck-Boost's operation time is shorter. When $U_{\mathrm{os}}>\sqrt{2} \quad U_{\mathrm{o}}$ (output voltage RMS value), the Buck-Boost converter stops working. When $U_{\mathrm{i}}<\left|u_{\mathrm{o}}\right|$, the voltage gain of the proposed TMCSI-BBC, the two mode controlled Z-source/Quasi-Z source inverter and TMCSI-QZ can be expressed in (4)-(6), respectively.

$$
\begin{gathered}
U_{\mathrm{o} \_ \text {TMCSI-BBC }}=U_{\mathrm{i}} /\left(1-d_{\mathrm{ST} 1}\right) \\
U_{\mathrm{o} \_\mathrm{Z} / \mathrm{QZ}}=U_{\mathrm{i}}\left(1-d_{\mathrm{ST} 1}\right) /\left(1-2 \cdot d_{\mathrm{ST} 1}\right) \\
U_{\mathrm{o} \_\mathrm{TMCSI}-\mathrm{QZ}}=U_{\mathrm{i}} /\left(1-2 \cdot d_{\mathrm{ST} 1}\right)
\end{gathered}
$$

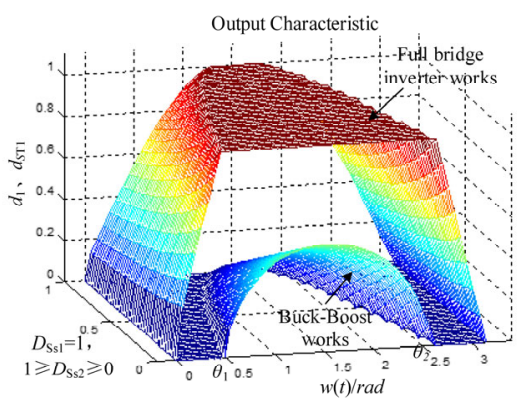

(a) $D \mathrm{ss}_{1}=1 、 1 \geq D \mathrm{ss} 2 \geq 0$

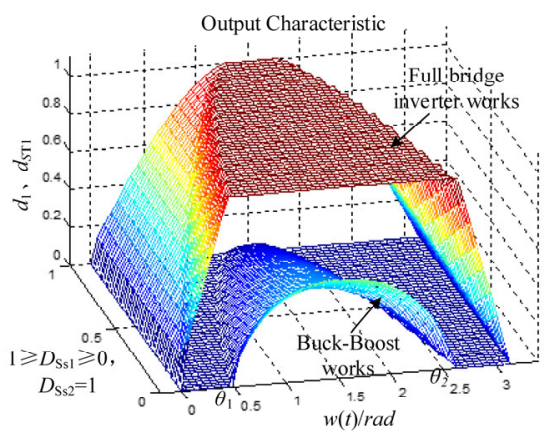

(b) $1 \geq D_{\mathrm{Ss} 1} \geq 0 、 \quad D_{\mathrm{Ss} 2}=1$

Fig. 10. Output characteristic of the proposed dual-input inverter.

\section{B. Design consideration}

When the Buck/Boost converter works, the devices $L_{\mathrm{f}}$ and $C_{\mathrm{f}}$ act as an additional filters, so a smaller $C_{1} / L_{1}$ can be chosen with a larger high-frequency voltage/current ripple. Ignoring the current of $C_{1}$, in steady state, the average current of $L_{1}$ in one high frequency period can be expressed as

$$
I_{\text {Llavg }}=\frac{u_{\mathrm{o}}}{R_{\mathrm{L}}\left(1-d_{\mathrm{ST} 1}\right)}
$$

where $R_{L}$ is the load resistance. 


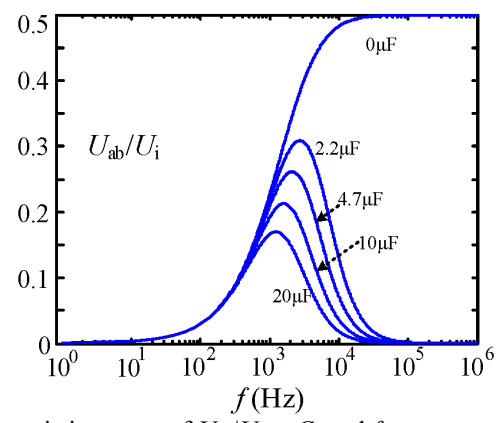

Fig. 11. Characteristic curves of $U_{\mathrm{ab}} / U_{\mathrm{i}}$ to $C_{1}$ and $f$.

Assuming the maximum current high-frequency ripple is about $60 \%$ of the maximum average current $I_{L 1 \text { avgmax }}, L_{1}$ can be derived as (8). In the dual-input application, the equivalent $U_{i}=U_{i 1}+U_{i 2}$.

$$
L_{1} \geq \frac{U_{\mathrm{i}}\left(\sqrt{2} U_{\mathrm{o}}-U_{\mathrm{i}}\right) U_{\mathrm{imin}} R_{\mathrm{Lmin}} T_{\mathrm{s}}}{60 \%\left(\sqrt{2} U_{\mathrm{o}}\right)^{3}}
$$

where $R_{\mathrm{Lmin}}$ is the minimum load resistance and $U_{\text {imin }}$ is the minimum input voltage.

In the same way, $L_{\mathrm{f}}$ can be derived in (9) based on the $40 \%$ of the maximum average output current. When $u_{\mathrm{o}}=U_{\mathrm{i}} / 2, L_{\mathrm{f}}$ gets the minimum value.

$$
L_{\mathrm{f}} \geq \frac{u_{\mathrm{o}}\left(U_{\mathrm{i}}-u_{\mathrm{o}}\right) R_{\mathrm{Lmin}} T_{\mathrm{s}}}{40 \% * 2 U_{\mathrm{i}} \sqrt{2} U_{\mathrm{o}}}
$$

When the full-bridge inverter works, $L_{1}$ is connected with $C_{1}$ in parallel, and the corresponding equivalent impedance is $Z_{\mathrm{L}}=s L_{1} /\left(1+s^{2} L_{1} C_{1}\right)$, where $s$ is the Laplace complex frequency. The impedance of $L C$-type output filter is $Z_{\mathrm{o}}=S L_{\mathrm{f}}+R_{\mathrm{o}} /\left(1+{ }_{S} C_{\mathrm{f}} R_{\mathrm{o}}\right)$. Assuming that $U_{\mathrm{ab}} / U_{\mathrm{i}}=Z_{\mathrm{L}} /\left(Z_{\mathrm{L}}+Z_{\mathrm{o}}\right)$, and the relationship between $u_{\mathrm{ab}} / U_{\mathrm{i}}, C_{1}$ and frequency $f$ is plotted in Fig. 11. It can be seen that when $C_{1}=0, U_{\mathrm{ab}} / U_{\mathrm{i}}$ is up to 0.5 in the intermediate and higher frequency range. With the increase of $C_{1}$, the band-stop frequency bands around the switching frequency get narrower. To obtain fast dynamic response and also reduce the reactive current, size/volume of the conversion system, $C_{1}=2.67 \mu \mathrm{F}$ is selected for the experimental prototype.

\section{Power relationship between the two inputs and output}

When the full-bridge inverter works, the load power $P_{\mathrm{o}}$ supplied by each inputs can be derived as

$$
\left\{\begin{array}{l}
P_{\mathrm{i} 1}=\frac{D_{\mathrm{Ss} 1} U_{\mathrm{i} 1}}{D_{\mathrm{Ss} 1} U_{\mathrm{i} 1}+D_{\mathrm{Ss} 2} U_{\mathrm{i} 2}} P_{\mathrm{o}} \\
P_{\mathrm{i} 2}=\frac{D_{\mathrm{Ss} 2} U_{\mathrm{i} 2}}{D_{\mathrm{Ss} 1} U_{\mathrm{i} 1}+D_{\mathrm{Ss} 2} U_{\mathrm{i} 2}} P_{\mathrm{o}}
\end{array}\right.
$$

When the Buck-Boost converter works, the average input current $i_{\mathrm{i} 2}$ of $U_{\mathrm{i} 2}$ under can be expressed as

$$
i_{\mathrm{i} 2}=D_{\mathrm{Ss} 2} I_{\text {Llavg }}
$$

The instantaneous output power $P_{\mathrm{o}}$ provided by $U_{\mathrm{i} 2}$ can be derived from (2), (7) and (11), and expressed as

$$
P_{\mathrm{i} 2}=D_{\mathrm{Ss} 2} U_{\mathrm{i} 2} I_{\mathrm{L} 1 \text { avg }}=D_{\mathrm{Ss} 2} U_{\mathrm{i} 2} \frac{u_{\mathrm{o}}}{\mathrm{R}_{\mathrm{L}}\left(1-d_{\mathrm{ST} 1}\right)}
$$

In (12), $P_{\mathrm{i} 2}$ is the function of $D_{\mathrm{Ss} 2}$ and $d_{\mathrm{ST} 1}$. In operating State I, $P_{\mathrm{i} 2}$ increases with increasing $D_{\mathrm{Ss} 2}$. In State II, $D_{\mathrm{Ss} 2}=1$, as $D_{\mathrm{Ss} 1}$ decreasing, $d_{\mathrm{ST} 1}$ will increase and $P_{\mathrm{i} 2}$ increase. Therefore, by adjusting $D_{\mathrm{Ssn}}$, the control strategy can realize power allocation for the two input sources, and allow $U_{\mathrm{i} 1}$ to track the MPP, and $P_{\mathrm{o}}$ supplied by $U_{\mathrm{i} 1}$ can be expressed as $P_{\mathrm{i} 1}=P_{\mathrm{o}}-P_{\mathrm{i} 2}$.

\section{EXPERIMENTAL RESULTS}

The proposed dual-input inverter based on TMCSI-BBC with master-slave power distribution has been constructed in laboratory and the corresponding experimental test is carried out. The $1^{\text {st }}$ input source $U_{\mathrm{i} 1}$ uses a programmable solar simulator TC.P.16.800.400.S to simulate PV cells and the $2^{\text {nd }}$ input $U_{\mathrm{i} 2}$ uses a power supply of 62012P-600-8 to supplement the load. The converter specifications as well as adopted components are listed in Table II. The prototype is shown in Fig. 12.

\begin{tabular}{lc}
\multicolumn{2}{c}{ TABLE II. PARAMETERS OF THE SINGLE/DUAL-INPUT PROTOTYPE. } \\
\hline Parameter/Elements & Value \\
\hline Rated Power & $0.5 \mathrm{kVA}$ \\
$U_{\mathrm{i}}$ (Single input) & $96-192 \mathrm{VDC}$ \\
$U_{\mathrm{i} 1} / U_{\mathrm{i} 2}$ (Dual input) & $96-148 \mathrm{VDC}$ \\
$u_{\mathrm{o}}$ & $220 \mathrm{VAC} 50 \mathrm{~Hz}$ \\
Switching Frequency & $25 \mathrm{kHz}$ \\
$L_{1}$ & $500 \mathrm{uH}$ \\
$C_{1}$ & $2.2 \mathrm{uF}+0.47 \mathrm{uF}$ \\
$L_{\mathrm{f}}$ & $800 \mathrm{uH}$ \\
$C_{\mathrm{f}}$ & $2.2 \mathrm{uF}$ \\
$\mathrm{S}_{\mathrm{T} 1}, \mathrm{~S}_{\mathrm{T} 2}$ and $\mathrm{S}_{1} \sim \mathrm{S}_{4}$ & $\mathrm{IXFQ} 34 \mathrm{~N} 50 \mathrm{P} 3$ \\
$\mathrm{~S}_{\mathrm{s} 1} 、 \mathrm{~S}_{\mathrm{s} 2}$ & AP18N20GS/P-HF \\
$\mathrm{D}_{\mathrm{s} 1} 、 \mathrm{D}_{\mathrm{s} 2}$ & $\mathrm{MBR} 20 \mathrm{H} 200 \mathrm{CT}$ \\
Control Circuit Chip & DSP TMS320F28335 \\
\hline
\end{tabular}

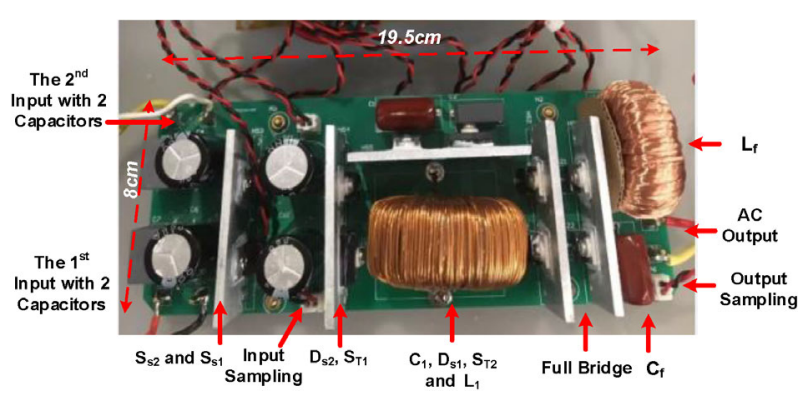

Fig. 12. Prototype of the proposed dual input inverter.

The maximum voltage stress over semiconductor devices of the proposed single-input TMCSI is $\sqrt{2} U_{0}$. However, the voltage stress of the dual-input inverter based on TMCSI-BBC is $\left(1-D_{\mathrm{Ss} 1}\right) U_{\mathrm{i} 1}+\sqrt{2} U_{\mathrm{o}}$ in BuckBoost mode under operating State II, where the full-bridge inverter have no switching spike voltage. To lower the voltage stress, $D_{\mathrm{Ss} 1}$ is limited at $1 \geq D_{\mathrm{Ss} 1} \geq 0.2$, which means the MPPT for $U_{\mathrm{i} 1}$ stops working under some extremely low power conditions like partial shading or cold rainy weather, and IXFQ34N50P3 with rated voltage of $500 \mathrm{~V}$ is chose for the proposed inverter. A $R C$ snubber, placed in front of the full-bridge inverter and connected in parallel, can also be used.

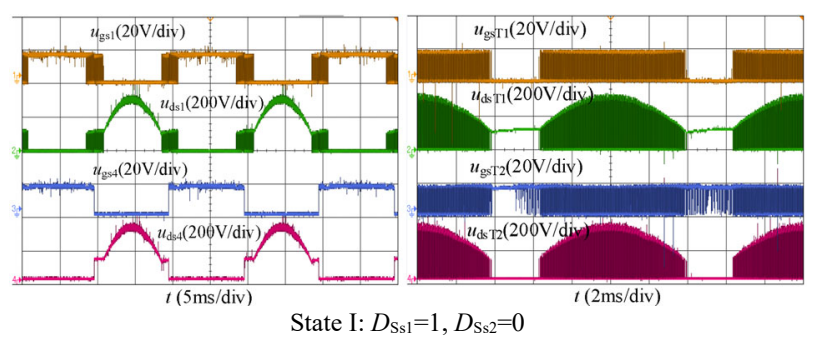



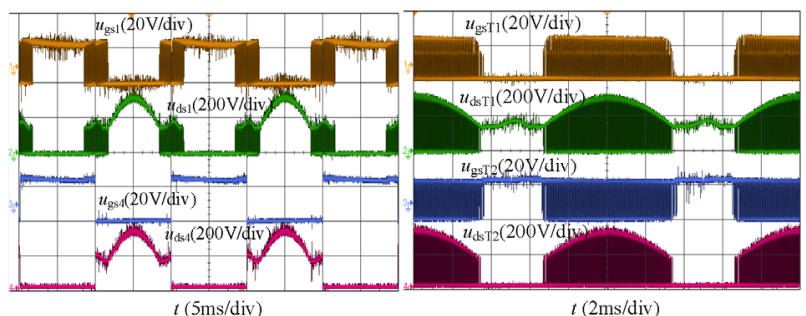

State I: $D_{\mathrm{ss} 1}=1, D_{\mathrm{ss} 2}=0.5$

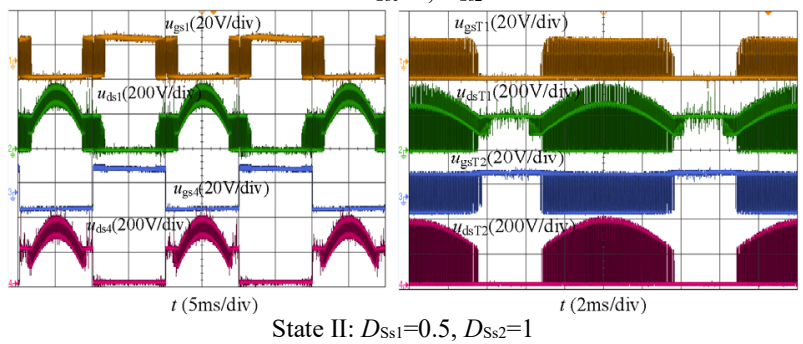

(a) Driver voltage $u_{\mathrm{gs} 1} 、 u_{\mathrm{gs} 4} 、 u_{\mathrm{gs} T 1} 、 u_{\mathrm{gs} T 2}$ and drain-source voltage $u_{\mathrm{ds} 1} 、 u_{\mathrm{ds} 4}$ 、 $u_{\mathrm{ds} T 1}, u_{\mathrm{ds} T 2}$ of the two states

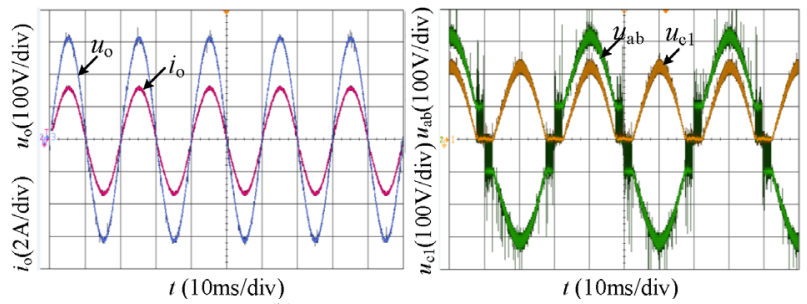

(b) State I: $D_{\mathrm{ss} 1}=1, D_{\mathrm{s} 2}=0$

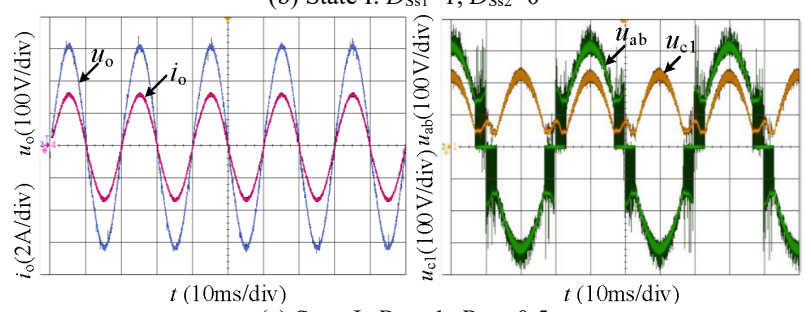

(c) State I: $D_{\mathrm{Ss} 1}=1, D_{\mathrm{S} s 2}=0.5$

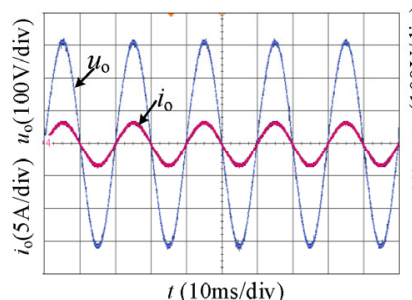

(d) State II: $D_{\mathrm{ss} 1}=0.5, D_{\mathrm{ss} 2}=1$

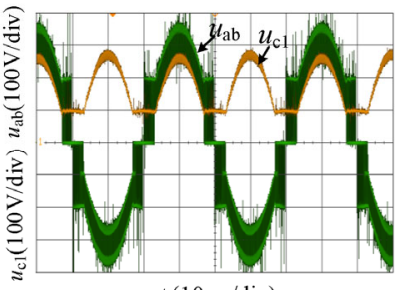

$t(10 \mathrm{~ms} / \mathrm{div})$

Fig. 13. Experimental waveforms of the proposed inverter with $U_{\mathrm{i} 1}=U_{\mathrm{i} 2}=96 \mathrm{~V}$ and output power of $500 \mathrm{~W}$ (rated load).

The steady-state experimental waveforms of the off-grid dual-input system with the rated resistive load are shown in Fig. 13. The experimental results show that: (1) $S_{4}$ remains ON in the positive half-cycle of $u_{\mathrm{o}}$. When $\left|u_{\mathrm{o}}\right|<U_{\mathrm{os}}, S_{\mathrm{T} 1}$ keeps $\mathrm{OFF}$ and $S_{\mathrm{T} 2}$ is $\mathrm{ON}$, the full-bridge inverter works in high frequency and $u_{\mathrm{ab}}$ is a PWM wave. When $\left|u_{\mathrm{o}}\right|>U_{\mathrm{os}}, S_{1}$ keeps $\mathrm{ON}, S_{\mathrm{T} 1}$ and $S_{\mathrm{T} 2}$ work in high frequency alternatively, and $u_{\mathrm{ab}}=D_{\mathrm{Ss} 1} U_{\mathrm{i} 1}+u_{\mathrm{C} 1}$. (2)When the full-bridge inverter works, the SPWM voltage is $U_{\mathrm{os}}=D_{\mathrm{Ss} 1} U_{\mathrm{i} 1}+D_{\mathrm{Ss} 2} U_{\mathrm{i} 2}$ as shown in Fig.13 (a), when the Buck-Boost converter works, the maximum drain-source voltage of $\mathrm{S}_{\mathrm{T} 1}$ in State II is $u_{\mathrm{dsT} 1}=D_{\mathrm{Ss} 1} U_{\mathrm{i} 1}+u_{\mathrm{c} 1}$, as shown in Fig. 13 (b). (4) By combining the two working modes, high quality $220 \mathrm{~V} / 50 \mathrm{~Hz} \mathrm{AC}$ waveforms are obtained

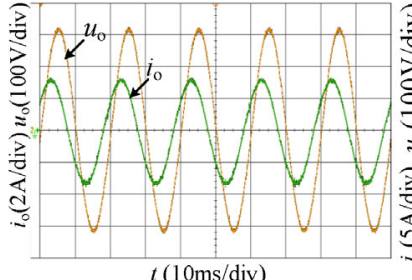

(a) Rated capacitive-resistive load $\cos \varphi=-0.75$

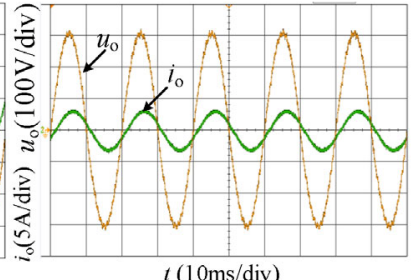

(b) Inductive-resistive load $\cos \varphi=0.89$
Fig. 14. Experimental waveforms of the proposed inverter under single input $U_{\mathrm{i} 1}=148 \mathrm{VDC}$ with reactive rated load.
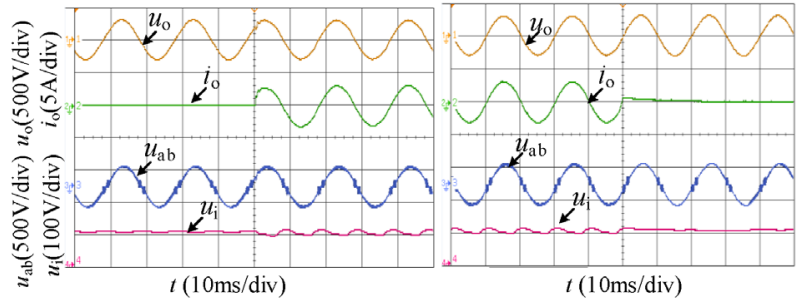

Fig. 15. Transient experimental waveforms with load abruptly changing from the rated resistive load to no load under single-input $U_{\mathrm{il}}=96 \mathrm{VDC}$.
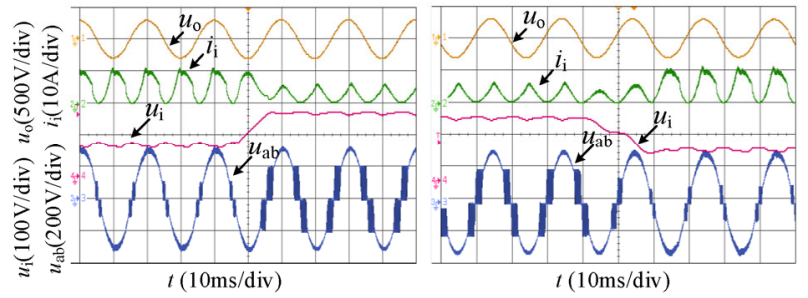

Fig. 16. Dynamic experimental waveforms with single-input $U_{\mathrm{i} 1}$ slowly changing between $96 \mathrm{~V}$ to $192 \mathrm{~V}$ under rated resistive load.

at output in each operating state by filtering $u_{\mathrm{ab}}$ with $L_{\mathrm{f}}, C_{\mathrm{f} \text {. }}$ (5) The working time of the full-bridge inverter increases with increasing $U_{\mathrm{os}}$, and the operating time of the Buck-Boost converter decreases, as shown in Fig. 13 (b)-(d). The experimental waveforms are in accordance with the theoretical analysis.

The experimental waveforms under single input $U_{\mathrm{i} 1}=148 \mathrm{VDC}$ with the rated reactive load are shown in Fig. 14. The experimental results show that the proposed inverter can achieve bidirectional power flow under single-input source, and has high-quality waveform of $u_{0}$.

The transient experimental waveforms with load abruptly changing from the rated resistive load to no load under single-input $U_{\mathrm{i} 1}=96 \mathrm{VDC}$ are shown in Fig. 15. The experimental results show that: When the load abruptly changes, the system has fast dynamic response, and the response time is about $0.6 \mathrm{~ms}$.

The dynamic experimental waveforms with single-input $U_{\mathrm{i} 1}$ slowly changing between $96 \mathrm{~V}$ to $192 \mathrm{~V}$ under rated resistive load are shown in Fig. 16. The results show that when $U_{\mathrm{i} 1}$ changes with a $10 \mathrm{~V} / \mathrm{ms}$ maximum speed (restrained by the Chroma $62100 \mathrm{H}-600$ Programmable DC source), the output $u_{\mathrm{o}}$ is unaffected, and the inverter achieves uniform distribution of duty ratio under the input voltage variation.

The transition experimental waveforms of the proposed off-grid system under the $1^{\text {st }}$ input MPP $(192 \mathrm{~W}, 96 \mathrm{~V})$ and the $2^{\text {nd }}$ input $U_{\mathrm{i} 2}=96 \mathrm{~V}$ with the resistive load abruptly changing 

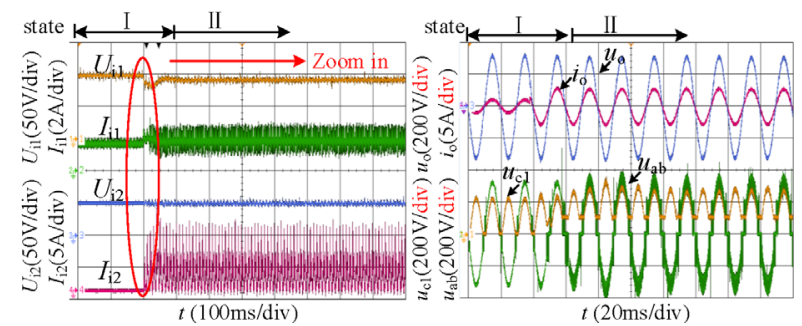

(a) Load abruptly changes from the light load to the rated one.

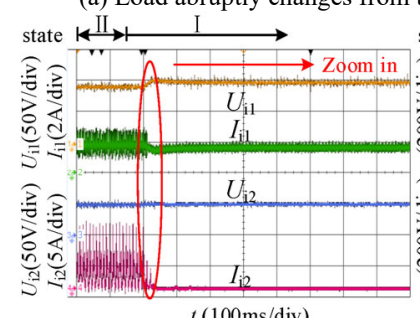

$t(100 \mathrm{~ms} / \mathrm{div})$

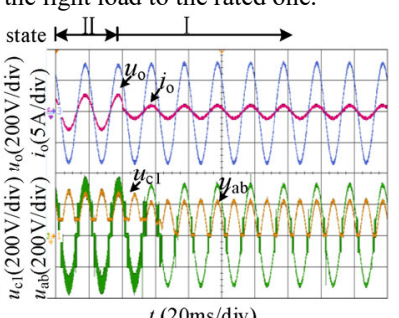

(b) Load abruptly changes from the rated load to the light one.

Fig. 17. Transition experimental waveforms of the proposed off-grid dual-input system with resistive load abruptly changing.

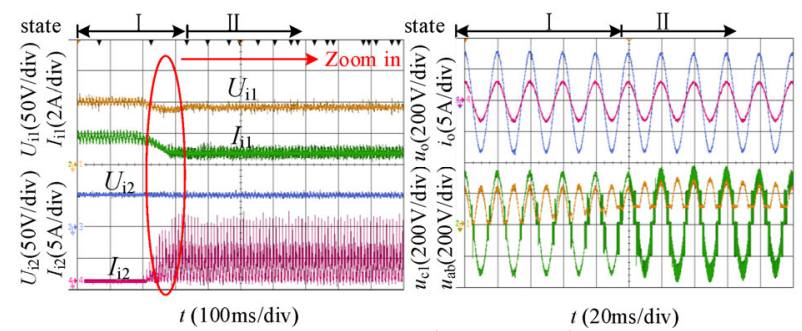

(a) From $1000 \mathrm{~W} / \mathrm{m}^{2}$ to $400 \mathrm{~W} / \mathrm{m}^{2}$

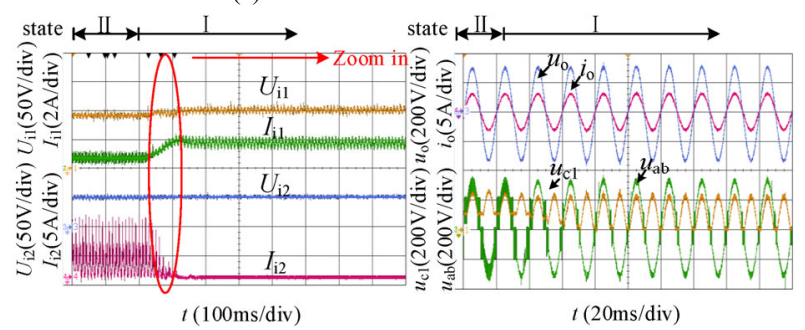

(b) From $400 \mathrm{~W} / \mathrm{m}^{2}$ to $1000 \mathrm{~W} / \mathrm{m}^{2}$

Fig. 18. Transition experimental waveforms among different operating states of the proposed off-grid system with abrupt light intensity change.

are shown in Fig. 17. In Fig. 17(a), firstly, the maximum output power of $U_{\mathrm{i} 1}$ is $P_{\mathrm{i} 1 \mathrm{M}}>\mathrm{P}_{\mathrm{o}}, U_{\mathrm{i} 1}$ supplies the light load alone. Once load increases to the rated, the $1^{\text {st }}$ input source tracks to its MPP $(96 \mathrm{~V}, 2 \mathrm{~A}, 192 \mathrm{~W})$, and $U_{\mathrm{i} 2}$ supplements the load. The system can smoothly changes from State I to State II. Fig. 17(b) shows that the smooth transition can also be realized as load changing from the rated one to the light one.

The transition experimental waveforms under the rated resistive load, the $1^{\text {st }}$ input MPP $(576 \mathrm{~W}, 96 \mathrm{~V})$ and the $2^{\text {nd }}$ $U_{\mathrm{i} 2}=96 \mathrm{~V}$ with abrupt light intensity change are shown in Fig. 18. In Fig. 18(a), at first, $P_{\mathrm{i} 1 \mathrm{M}}>P_{\mathrm{o}}=0.5 \mathrm{~kW}$, and $U_{\mathrm{i} 1}$ supplies the load alone. With the light intensity decreases, once the power supplied by $U_{\mathrm{i} 1}$ is insufficient, $U_{\mathrm{i} 2}$ starts supplying the load to help $U_{\mathrm{i} 1}$ track its MPP, and the system can smoothly transits from State I to State II. Fig. 18(b) shows that the transition can also be smooth as the light intensity increases from $400 \mathrm{~W} / \mathrm{m}^{2}$ to $1000 \mathrm{~W} / \mathrm{m}^{2}$.

The conversion efficiency and output voltage THD curves of the inverter prototype with different resistive load are measured and plotted in Fig. 19. In Fig. 19 (a), the efficiency

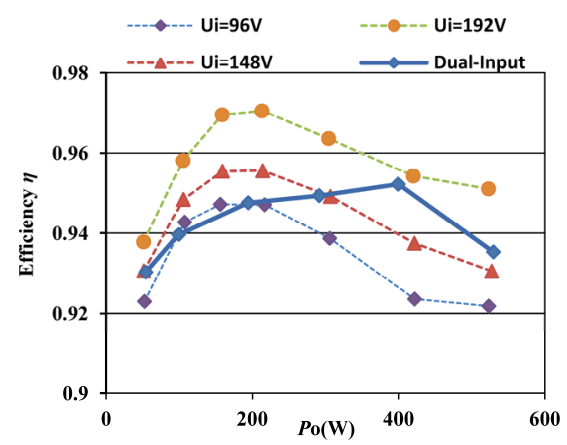

(a) Measured efficiency

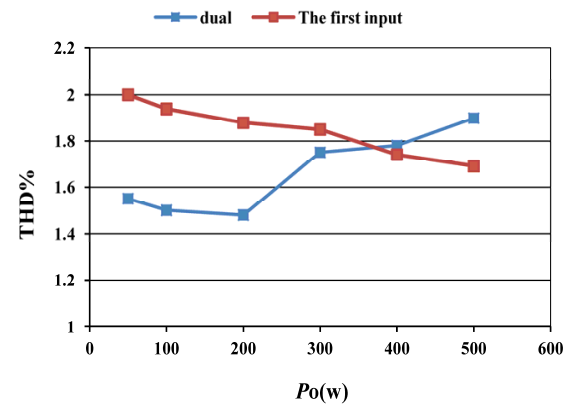

(b) Output voltage THD with resistive load.

Fig. 19. Efficiency and THD Measurement.

curves under different single-input voltage $U_{\mathrm{i}}=96 \mathrm{~V}, 148 \mathrm{~V}$ and $192 \mathrm{~V}$ and dual-input supply $U_{\mathrm{i} 1}(192 \mathrm{~W}, 96 \mathrm{~V}) / U_{\mathrm{i} 2}(96 \mathrm{~V})$ are presented, respectively.

It can be seen that: (1) The conversion efficiency all increase first and then decrease with the load power increases, for the hard-switching loss of power switches at light load, and increasing conduction loss of devices under heavy load. (2) With the input voltage increasing, the conversion efficiency increases, since the power loss of device caused by boosting input voltage of the Buck-Boost converter decreases. (3) The conversion efficiency under three different single-input voltage $96 \mathrm{~V}, 144 \mathrm{~V}, 192 \mathrm{~V}$ with the rated load is $92.5 \%, 93 \%, 95.5 \%$ respectively, and the maximum efficiency is $94.5 \%, 95.7 \%, 97 \%$, respectively. 4) The maximum and full-load conversion efficiencies under dual inputs are $95.2 \%$ and $93.3 \%$, respectively. Fig. 19(b) shows the output voltage THD curves under the dual-input source $U_{\mathrm{i} 1}(192 \mathrm{~W}, 96 \mathrm{~V}) / U_{\mathrm{i} 2}(96 \mathrm{~V})$, it shows that: (1) The output THD under the $1^{\text {st }}$ input decreases with the load increasing, and THD under the dual inputs decreases first, and then increases, which is mainly because the effect of output filter is weakened in State II. (2) The minimum and full-load THD of $u_{\mathrm{o}}$ under dual-input supply is $1.48 \%$ and $1.9 \%$ respectively, while under the $1^{\text {st }}$ input is all $1.69 \%$.

Combining the two working modes, the proposed inverter achieves uniform distribution of duty ratio under single/dual input with wide range varied input voltage. For $\mathrm{S}_{\mathrm{T} 1}, \mathrm{~S}_{\mathrm{T} 2}$ and $\mathrm{S}_{1} \sim \mathrm{S}_{4}$, only a pair of switches operate in high frequency at a

TABLE III. COMPARISON WITH OTHER INVERTERS.

\begin{tabular}{|c|c|c|c|c|}
\hline Configuration & $\begin{array}{c}\text { Equivalent } \\
\text { input voltage }\end{array}$ & $\begin{array}{c}\text { Maximum } \\
\text { efficiency }\end{array}$ & Type & $\begin{array}{c}\text { Power allocation } \\
\text { for the inputs ? }\end{array}$ \\
\hline $\begin{array}{c}\text { Propused dual-input } \\
\text { step-up inverter }\end{array}$ & $U_{\mathrm{i}}=192 \mathrm{~V}$ & $\sim 97 \%$ & Buck Boost & Yes \\
\hline CTPS in [17] & $U_{\mathrm{i}}=190 \mathrm{~V}$ & $\sim 95 \%$ & Buck-Boost & No \\
\hline DP-AMI proposed in [17] & $U_{\mathrm{i}}=190 \mathrm{~V}$ & $\sim 97 \%$ & Buck & No \\
\hline
\end{tabular}


certain time as discussed in Section III-B, and therefore the inverter can achieve high average efficiency.

Compared with DP-AMI proposed in [17] and the conventional two-stage dc/ac power system (CTPS) under the same experimental conditions, the proposed inverter has better comprehensive performance, and comparison results are listed in Table III. Maximum conversion efficiency of CTPS $(\sim 95 \%)$ is lower than the proposed one $(\sim 97 \%)$. DP-AMI is just a buck-type inverter when powered by two input sources, and can also not realize power allocation between the two inputs. Its maximum efficiency is almost the same as the proposed under the same input voltage, but conversion efficiency under light load is relatively lower compared to the inverter in this paper due to the inherent power loss caused by the front-end boost converter.

\section{CONCLUSION}

A novel two-mode controlled step-up inverter with high efficiency was proposed and verified in this paper. Based on low impedance of the intermediate capacitive link under high frequency, a new power flow path between the low-voltage input source and the ac output side is constructed. When the instantaneous value $u_{\mathrm{o}}$ is lower than input voltage $U_{\mathrm{i}}$, the input source can supply the ac load directly. When $u_{\mathrm{o}}>U_{\mathrm{i}}$, the intermediate capacitive link boosts the input voltage, and supply the ac load with $U_{\mathrm{i}}$ directly. This solution was realized by proposing a family of TMCSI. With the proposed TMCSI, the input power is processed without the front-end $\mathrm{dc} / \mathrm{dc}$ set-up converter, and the conversion stage is reduced, which is beneficial for the reducing current/voltage stress, switching losses and size/volume of the conversion system.

The dual-input inverter based on TMCSI-BBC with a novel power allocation method is also studied to improve load capability. This power allocation method is controlled separately from the two-mode control strategy by adjusting $D_{\text {Ssn }}$ with line frequency, which can help to improve the dual-input system's reliability, since there is no overshoot issue anymore. The proposed dual-input set-up inverter has two operating states, and each state consists of two working modes. The designed and developed 500VA 96-192VDC input and $220 \mathrm{~V} 50 \mathrm{~Hz} \mathrm{AC}$ inverter prototype has excellent comprehensive performance, and the experimental results are consistent with the theoretical analysis. The maximum achieved efficiency is $97 \%$ and the output voltage THD is lower than $2 \%$ over the entire power range.

\section{REFERENCES}

[1] X. Zhou, J. Xu, and S. Zhong, "Single-Stage Soft-Switching Low-Distortion Bipolar PWM Modulation High-Frequency-Link DC-AC Converter With Clamping Circuits," IEEE Trans. Industrial Electron., vol. 65, no. 10, pp. 7719-7729, Oct. 2018.

[2] E. Babaei, E. Asl Shokati, and M. Hasan Babayi, "Steady-State and Small-Signal Analysis of High-Voltage Gain Half-Bridge Switched Boost Inverter," IEEE Trans. Industrial Electron., vol. 63, no. 6, pp. 3546-3553, June 2016.

[3] Z Zhang, Z Ouyang, O. C. Thomsen, M. A. E. Andersen. "Analysis and design of a bidirectional isolated DC-DC converter for fuel cells and super capacitors hybrid system", IEEE Trans. Power Electron., vol. 27, no. 2, pp. 848-859, Feb. 2012.

[4] M. C Mira, Z. Zhang, A. Knott, M. A. E. Andersen. "Analysis, design, modeling, and control of an interleaved-boost full-bridge three-port converter for hybrid renewable energy systems", IEEE Trans. Power Electron., vol. 32, no. 2, pp. 1138-1155, Feb. 2017.

[5] B. D. Reddy, M. P. Selvan and S. Moorthi. "Design, Operation, and Control of S3 Inverter for Single-Phase Microgrid Applications," IEEE Trans. Industrial Electron., vol. 62, no. 9, pp. 5569-5577, Sept. 2015.

[6] G. Franceschini, E. Lorenzani and G. Buticchi. "Saturation Compensation Strategy for Grid Connected Converters Based on Line Frequency Transformers," IEEE Trans. Energy Conversion, vol. 27, no. 2, pp. 229-237, June 2012.

[7] Q. Li and P. Wolfs. "A Review of the Single Phase Photovoltaic Module Integrated Converter Topologies With Three Different DC Link Configurations," IEEE Trans. Power Electron., vol. 23, no. 3, pp. 1320-1333, May 2008.

[8] H. Hu, S. Harb and N. Kutkut, et al, "A Review of Power Decoupling Techniques for Microinverters With Three Different Decoupling Capacitor Locations in PV Systems," IEEE Trans. Power Electron., vol. 28, no. 6, pp. 2711-2726, June 2013.

[9] A. I. Bratcu, I. Munteanu, S. Bacha, et al, "Cascaded DC-DC Converter Photovoltaic Systems: Power Optimization Issues," IEEE Trans. Industrial Electron., vol. 58, no. 2, pp. 403-411, Feb. 2011.

[10] T. Dragicevic, X. Lu, J. C. Vasquez, et al, "DC Microgrids-Part II: A review of power architectures, applications, and standardization issues," IEEE Trans. Power Electron., vol. 31, no. 5, pp. 3528-3549, May 2016.

[11] L. Diao, H. Du, Z. Shu, et al, "A Comparative Study Between AI-HM and SPD-HM for Railway Auxiliary Inverter With Pulsating DC Link," IEEE Trans. Industrial Electron., vol. 65, no. 7, pp. 5816-5825, July 2018.

[12] W. Li, L. Fan, Y. Zhao, et al, "High-Step-Up and High-Efficiency Fuel-Cell Power-Generation System With Active-Clamp Flyback-Forward Converter," IEEE Trans. Industrial Electron., vol. 59, no. 1, pp. 599-610, Jan. 2012.

[13] J. Kan, S. Xie, Y. Wu, et al, "High-Frequency-Link Inverter Using Combined Synchronous Rectifiers," IEEE Trans. Industrial Electron., vol. 61, no. 12, pp. 6769-6777, Dec. 2014.

[14] D. Chen and S. Chen, "Combined Bidirectional Buck-Boost DC-DC Chopper-Mode Inverters With High-Frequency Link," IEEE Trans. Industrial Electron., vol. 61, no. 8, pp. 3961-3968, Aug. 2014.

[15] Z. Chen, Y. Chen and B. Zhang, "An Equivalent Voltage Source Placement Rule for Impedance Source Network and Performance Assessment," IEEE Trans. Industrial Electron., vol. 65, no. 10, pp. 8382-8392, Oct. 2018.

[16] V. Jagan, J. Kotturu and S. Das, "Enhanced-Boost Quasi-Z-Source Inverters With Two-Switched Impedance Networks," IEEE Trans. Industrial Electron., vol. 64, no. 9, pp. 6885-6897, Sept. 2017.

[17] H. Wu, L. Zhu and F. Yang, et al, "Dual-DC-Port Asymmetrical Multilevel Inverters With Reduced Conversion Stages and Enhanced Conversion Efficiency," IEEE Trans. Industrial Electron., vol. 64, no. 3, pp. 2081-2091, March 2017.

[18] A. Lashab, D. Sera and J. Martins, et al, "Multilevel DC-Link Converter-Based Photovoltaic System with Integrated Energy Storage," 2018 5th International Symposium on Environment-Friendly Energies and Applications (EFEA), Rome, 2018, pp. 1-6.

[19] A. Nazemi Babadi, O. Salari, and M. J. Mojibian, et al, "Modified Multilevel Inverters With Reduced Structures Based on PackedU-Cell," IEEE Journal of Emerging and Selected Topics in Power Electron., vol. 6, no. 2, pp. 874-887, June 2018.

[20] A. Lashab et al, "Cascaded Multilevel PV Inverter with Improved Harmonic Performance During Power Imbalance Between Power Cells," IEEE Trans. Industry Applications, vol. 56, no. 3, pp. 2788-2798, May-June 2020. 